\title{
Complete FcRn dependence for intravenous Ig therapy in autoimmune skin blistering diseases
}

\author{
Ning Li, ${ }^{1}$ Minglang Zhao, ${ }^{1}$ Julio Hilario-Vargas, ${ }^{1}$ Phillip Prisayanh, ${ }^{1}$ \\ Simon Warren, ${ }^{1}$ Luis A. Diaz, ${ }^{1}$ Derry C. Roopenian, ${ }^{2}$ and Zhi Liu' ${ }^{1,3}$
}

\begin{abstract}
${ }^{1}$ Department of Dermatology, University of North Carolina at Chapel Hill School of Medicine, Chapel Hill, North Carolina, USA. ${ }^{2}$ The Jackson Laboratory,
\end{abstract} Bar Harbor, Maine, USA. ${ }^{3}$ Microbiology and Immunology, University of North Carolina at Chapel Hill School of Medicine, Chapel Hill, North Carolina, USA.

\begin{abstract}
Numerous mechanisms of action have been proposed for intravenous Ig (IVIG). In this study, we used IgG passive transfer murine models of bullous pemphigoid (BP), pemphigus foliaceus (PF), and pemphigus vulgaris (PV) to test the hypothesis that the effect of IVIG in autoantibody-mediated cutaneous bullous diseases is to accelerate the degradation of pathogenic IgG by saturation of the MHC-like Fc receptor neonatal Fc receptor (FcRn). BP, $\mathrm{PF}$, and PV are organ-specific antibody-mediated diseases in which autoantibodies target the hemidesmosomal antigen BP180 and desmosomal antigens Dsg1 and Dsg3, respectively. Antibodies against BP180, Dsg1, and Dsg3, when injected into neonatal mice, induce the BP, PF, and PV disease phenotypes, respectively. We found that FcRn-deficient mice were resistant to experimental BP, PF, and PV. Circulating levels of pathogenic IgG in FcRndeficient mice were significantly reduced compared with those in WT mice. Administration of high-dose human IgG (HDIG) to WT mice also drastically reduced circulating pathogenic IgG levels and prevented blistering. In FcRn-deficient mice, no additional protective effect with HDIG was realized. These data demonstrate that the therapeutic efficacy of HDIG treatment in the pemphigus and pemphigoid models is dependent on FcRn. Thus, FcRn is a promising therapeutic target for treating such IgG-mediated autoimmune diseases.
\end{abstract}

\section{Introduction}

Pemphigus and pemphigoid are autoimmune skin blistering diseases. Pemphigoid is characterized by subepidermal blisters, inflammatory cell infiltration, and the linear deposition of IgG autoantibodies and complement components at the basement membrane zone (1). Bullous pemphigoid (BP) is by far the most common autoimmune subepidermal blistering disease. $\mathrm{BP}$ autoantibodies recognize 2 hemidesmosomal components, BP180 and BP230 (1). BP230 (also referred to as BPAg1) is an intracellular protein that localizes to the hemidesmosomal plaque $(2,3)$. In contrast, BP180 (also referred to as BPAG2 or type XVII collagen) is a transmembrane protein $(4,5)$. The extracellular region of BP180 consists of 15 collagen domains separated from one another by non-collagen sequences. BP180-specific autoantibodies predominantly target epitopes located within the NC16A region of the ectodomain of the molecule $(6,7)$. Pemphigus is characterized by intraepidermal blisters and epidermis-specific autoantibodies (8). The 2 major forms of the disease are pemphigus foliaceus $(\mathrm{PF})$ and pemphigus vulgaris $(\mathrm{PV})$. In $\mathrm{PF}$, blisters occur in the superficial epidermis (subcorneal blister), whereas in PV the epidermal cell separation occurs just above the basal layer of the epidermis (suprabasal blister). PF and PV autoantibodies recognize predominantly desmoglein 1 (Dsg1) and Dsg3, 2 transmembrane glycoproteins components of the desmosome, respectively (9). Reactivity of pemphigus autoantibodies with proteins other than Dsg1 and

Nonstandard abbreviations used: BP, bullous pemphigoid; Dsg1, desmoglein 1; FcRn, neonatal Fc receptor; HDIG, high-dose human IgG; IF, immunofluorescence; ITP, idiopathic thrombocytic purpura; IVIG, intravenous IgG; $\beta_{2} \mathrm{~m}, \beta_{2}$-microglobulin; mBP180, murine BP180 antigen; MPO, myeloperoxidase; PF, pemphigus foliaceus; PF1, PF patient 1; PV, pemphigus vulgaris; PV1, PV patient 1.

Conflict of interest: The authors have declared that no conflict of interest exists.

Citation for this article: J. Clin. Invest. 115:3440-3450 (2005).

doi:10.1172/JCI24394.
Dsg3 and the pathogenic potential of these autoantibodies have been documented (10-12). Pathogenicity of the anti-Dsg1, anti-Dsg3, and anti-BP180 antibodies has been demonstrated in IgG passive transfer mouse models. Neonatal mice injected with these pathogenic antibodies develop PF-, PV-, and BP-like skin disease phenotypes, respectively, at both clinical and histological levels (13-17). Subepidermal blistering in experimental BP depends on complement activation, mast cell degranulation, and neutrophil infiltration (18-20).

The conventional therapy for autoimmune diseases, including pemphigus and pemphigoid, has been high-dose, long-term systemic corticosteroids and immunosuppressive agents (21-23). However, long-term treatment with these drugs may cause many dose-related adverse effects (24). Intravenous Ig (IVIG) has been shown to be effective for the treatment of a variety of immune-mediated inflammatory diseases (25), including autoimmune cytopenias, GuillainBarré syndrome, multiple sclerosis, myasthenia gravis, anti-factor VIII autoimmune disease, dermatomyositis, Kawasaki disease, vasculitis, uveitis, and graft-versus-host disease (26-32). Recently, IVIG has also been reported to treat a small group of patients with human autoimmune blistering diseases, including pemphigus and pemphigoid $(33,34)$. However, the use of IVIG in these blistering diseases is still controversial, and no controlled study has been done on the efficacy of IVIG in the treatment of these diseases.

Numerous mechanisms have been proposed to explain the mode of action of IVIG, including regulation of functions of Fc receptors, attenuation of complement-mediated tissue damage, neutralization of autoantibodies by antiidiotypic antibodies, interference with the cytokine network, and modulation of effector functions of T and B cells (35-40) and/or the reticuloendothelial system (41). It has also been proposed that the beneficial action of IVIG in antibody-mediated disorders is due to its enhancement of IgG catabolism, leading to an accelerated pathogenic autoantibody clearance 
Table 1

Optimal doses of anti-mBP180, anti-Dsg1, and anti-Dsg3 in mice ${ }^{A}$

$\begin{array}{lccc}\text { Antibody } & \begin{array}{c}\text { IgG dose } \\ (\mu \mathbf{g} / \mathbf{g} \\ \text { body weight) }\end{array} & \begin{array}{c}\text { No. of } \\ \text { mice }\end{array} & \begin{array}{c}\text { Clinical } \\ \text { disease score } \\ \text { (mean } \pm \text { SEM) }\end{array} \\ \text { Anti-mBP180 } & 50 & 4 & 2.88 \pm 0.10 \\ & 25^{\mathrm{B}} & 4 & 1.63 \pm 0.13 \\ & 12.5 & 4 & 0.63 \pm 0.13 \\ \text { Anti-Dsg1 (PF1) } & 6.25 & 4 & 0.00 \pm 0.00 \\ & 100 & 4 & 3.00 \pm 0.00 \\ & 50 & 4 & 2.25 \pm 0.14 \\ \text { Anti-Dsg1 (PF2) } & 40^{\mathrm{B}} & 4 & 1.38 \pm 0.13 \\ & 25 & 4 & 0.25 \pm 0.14 \\ & 100 & 4 & 2.50 \pm 0.20 \\ \text { Anti-Dsg3 (PV1) } & 50^{\mathrm{B}} & 4 & 1.38 \pm 0.13 \\ & 40 & 4 & 0.50 \pm 0.00 \\ & 25 & 4 & 0.00 \pm 0.00 \\ & 100 & 4 & 2.88 \pm 0.13 \\ & 60 & 4 & 1.88 \pm 0.13 \\ \text { Anti-Dsg3 (PV2) } & 50^{\mathrm{B}} & 4 & 1.38 \pm 0.13 \\ & 25 & 4 & 0.00 \pm 0.00 \\ & 100 & 4 & 1.75 \pm 0.14 \\ & 60^{\mathrm{B}} & 4 & 1.25 \pm 0.14 \\ & 50 & 4 & 0.75 \pm 0.14 \\ & 25 & 4 & 0.00 \pm 0.00 \\ & & & \end{array}$

ANeonatal WT mice were injected i.p. with pathogenic anti-mBP180, anti-Dsg1, or anti-Dsg3 lgG ( $\mu \mathrm{g} / \mathrm{g}$ body weight). Injected animals were examined clinically 48 hours after IgG injection, and disease activity was scored, averaged in each group, and expressed as mean disease score \pm SEM (see Methods for more details). There was a significant difference in clinical disease scores between mice with blisters and mice without blisters $(P<0.0001)$. ${ }^{B}$ Optimal dose of pathogenic IgG, which induces clinical blisters and gives the most sensitive dose response.

(42-47). In experimental autoimmune idiopathic thrombocytic purpura (ITP) and the $\mathrm{K} / \mathrm{BxN}$ mouse model of arthritis, IVIG has been suggested to protect against disease both by the saturation of the MHC-like class I Fc receptor and by recruitment of the inhibitory Fc receptor Fc $\mathrm{RIIb}$ (47-50). Which mechanism(s) prevail in other autoantibody-mediated diseases remains to be determined.

Fc $\gamma$ RIIb receptors are single-chain molecules bearing IgG-binding sites in their extracellular domains and cytoplasmic domains containing an immunoreceptor tyrosine inhibition motif. Fc $\gamma$ RIIb deficiency is associated with increased susceptibility and severity to organ-specific and systemic autoimmune diseases, such as ITP, glomerulonephritis, arthritis, and lupus (51-54). Neonatal $\mathrm{Fc}$ receptor $(\mathrm{FcRn})$ is a heterodimer of $\beta_{2}$-microglobulin $\left(\beta_{2} \mathrm{~m}\right)$ and a $45-\mathrm{kDa} \alpha$ chain closely related to MHC class I (55). FcRn is expressed broadly, including in the placenta, intestine, and various vascular endothelia (56-58). It mediates the transport of maternal IgG across the placenta during gestation and across the intestine in neonates. FcRn is also responsible for the maintenance of serum IgG levels by binding and protecting IgG against lysosomal degradation (57-64). Mice lacking $\beta_{2} \mathrm{~m}\left(\beta_{2} \mathrm{~m}^{-/-}\right.$mice) or the $\alpha$ chain $\left(\mathrm{FcRn}^{-1-}\right.$ mice) eliminate IgG several times faster than normal, resulting in reduced levels of circulating $\operatorname{IgG}(58,62-65)$. Consistent with rapid elimination of $\operatorname{IgG}$, we previously showed that mice deficient in $\beta_{2} \mathrm{~m}$, the light chain for all MHC class I family proteins, are resistant to experimental $\mathrm{BP}(66)$. In this study, we investigated potential mechanism(s) of IVIG action in antibody-mediated pemphigus and pemphigoid using mice deficient in the heavy chain of FcRn and FcyRIIb. Our studies show a striking example in which the therapeutic benefits of IVIG can be attributed to FcRn.

\section{Results}

High-dose human IgG treatment accelerates degradation of pathogenic antimurine BP180, anti-Dsg1, and anti-Dsg3 IgG and abolishes skin lesions. To better quantify the effect of high-dose human IgG (HDIG) on experimental BP, PF, and PV, we first established an optimal dose for these pathogenic IgG preparations in neonatal mice, at which clear-cut clinical disease was present but pathogenic antibody was not used in excess. Mice were injected i.p. with different amounts of pathogenic antibody and examined clinically 48 hours later. The optimal doses are listed in Table 1 and were used for all experiments in this study. In experimental BP, mice injected with pathogenic antimurine BP180 (anti-mBP180) IgG (25 $\mu \mathrm{g} / \mathrm{g}$ body weight) developed typical BP skin lesions (subepidermal blisters) clinically (Figure 1A) and histologically (Figure 1B). In contrast, mice pretreated with HDIG and injected with an identical dose of pathogenic IgG showed a reduced disease phenotype, and the disease phenotype was completely abolished at higher doses (Figure $1, \mathrm{C}-\mathrm{G}$ ). A dose of $0.5 \mathrm{mg} / \mathrm{g}$ body weight HDIG reduced skin clinical disease score from $1.68+$ down to 0 , with a minimal degree of microscopic dermal-epidermal separation (Figure 1, C and D). Treatment with 1 and $2 \mathrm{mg}$ HDIG completely blocked pathogenic activity of anti-mBP180 IgG (Figure 1, E-G). The severity of BP skin blistering is directly correlated to number of infiltrating neutrophils (19). Quantification of neutrophil infiltration by the neutrophil cell marker myeloperoxidase (MPO) assay showed significant reduction in the enzyme activity at the injection site in the HDIG-treated mice compared with diseased mice (Figure 1H). ELISA assay revealed a significant reduction in circulating pathogenic anti-mBP180 IgG levels in HDIG-treated mice compared with diseased mice (Figure 1I). As a control, mice pretreated with the same dose of IgM as HDIG showed similar levels of serum anti-mBP180 IgG and the same degree of clinical disease as compared with the diseased mice (Figure 1 and Table 2).

In experimental PF, anti-Dsg 1 antibody (40 and $50 \mu \mathrm{g} / \mathrm{g}$ body weight for PF patient 1 [PF1] and PF2, respectively) induced subcorneal blisters, a hallmark of PF in mice (Figure 2, A and B and Table 2). In contrast, mice pretreated with HDIG followed by the same dose of pathogenic IgG failed to develop skin lesions (Figure 2, $\mathrm{C}$ and D). Pathogenic anti-Dsg1 IgG levels in circulation in the HDIG-treated mice were significantly reduced (Figure 2E). Similarly, in experimental PV, anti-Dsg3 antibody (50 and $60 \mu \mathrm{g} / \mathrm{g}$ body weight for PV patient 1 [PV1] and PV2, respectively) induced suprabasal blisters, a hallmark of PV in mice (Figure 2, F and G and Table 2). In contrast, mice pretreated with HDIG followed by the same dose of pathogenic IgG failed to developed skin lesions (Figure 2, H and I). Pathogenic anti-Dsg3 IgG levels in circulation in the HDIG-treated mice were significantly reduced (Figure 2J). As a control, mice pretreated with the same dose of IgM as HDIG showed similar degrees of clinical disease as compared with the diseased PF and PV mice (Figure 2 and Table 2). These results are consistent with the hypothesis that HDIG treatment prevents antibody-induced blister formation by increasing pathogenic IgG degradation.

This hypothesis predicts an increased catabolism of total rabbit IgG (for the BP model) and human autoantibody IgG (for the PF and PV models) in the HDIG-treated mice. The next set of experiments proved this was the case. Rabbit IgG-specific and anti-mBP180-spe- 


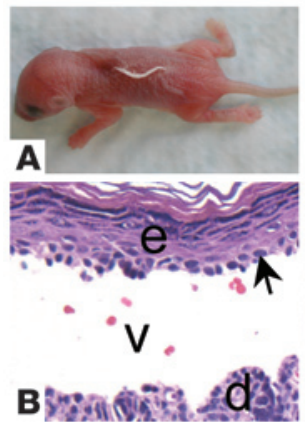

None

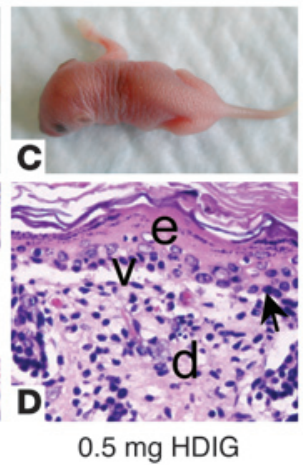

H

H $1.6 \quad=+\lg M$

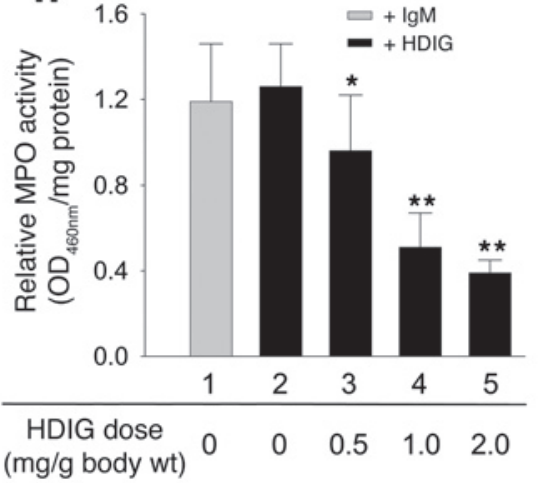

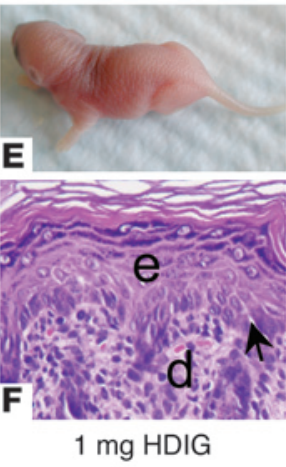

I

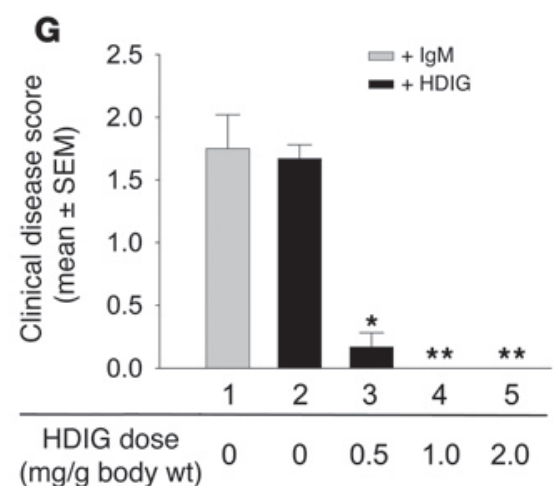

(mg/g body wt)

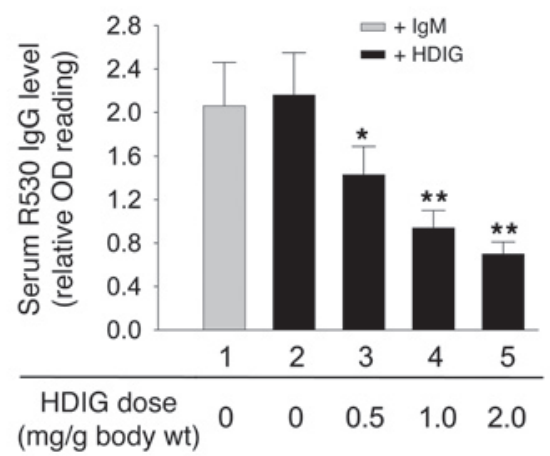

\section{Figure 1}

High-dose Ig inhibits experimental BP by accelerating degradation of pathogenic anti-mBP180 IgG. Neonatal C57BL/6J mice were pretreated with buffer, IgM (12.93 mg/g body weight), or different doses of HDIG (0-2 mg/g body weight) and injected i.p. with pathogenic lgG ( $25 \mu \mathrm{g} / \mathrm{g}$ body weight) 2 hours later. The animals were examined 48 hours after pathogenic IgG injection. Control mice showed typical BP clinically (A) and histologically (B). In contrast, mice pretreated with HDIG were protected from BP, and the protective effect was dose dependent (C-F). (G) HDIG treatment resulted in significant reduction in clinical skin disease (bars 3-5) as compared with IgM (bar 1) and buffer controls (bar 2). (H) MPO assays revealed a significant reduction in neutrophil infiltration in mice treated with HDIG (bars 3-5) as compared with control mice (bars 1 and 2). (I) ELISA showed a similar pattern of reduction in circulating pathogenic lgG in mice treated with HDIG (bars 3-5) relative to controls (bars 1 and 2). $n=8$ in each group. ${ }^{\star} P<0.05 ;{ }^{*} P<0.001$. e, epidermis; d, dermis; $v$, vesicle. Arrow indicates site of pathogenic antibody binding.

cific ELISA assays showed similar decreases in total and antigenspecific rabbit IgG levels in the HDIG-treated mice: decreases in relative $O D$ reading for total rabbit IgG versus the relative OD reading for $\mathrm{mBP} 180$-specific rabbit IgG at different HDIG doses were $0.98 \pm 0.11$ versus $0.73 \pm 0.21(0.5 \mathrm{mg}$ HDIG; $P=0.32), 1.37 \pm 0.19$ versus $1.34 \pm 0.14$ ( $1 \mathrm{mg}$ HDIG; $P=0.89)$, and $1.68 \pm 0.11$ versus $1.50 \pm 0.18$ ( $2 \mathrm{mg}$ HDIG; $P=0.39$ ). The rate of increased catabolism (expressed as percent decrease) of total rabbit IgG and anti-mBP180 IgG in the HDIG-treated mice was also very similar: percent decreases in total IgG versus $\mathrm{mBP} 180$-specific IgG were $42 \%$ versus $32 \%$ (0.5 mg HDIG; $P=0.22)$, 59\% versus $61 \%$ (1.0 mg HDIG; $P=0.57$ ), and $73 \%$ versus $68 \%$ (2.0 mg HDIG; $P=0.39)$. Since PF and PV autoantibodies used in these experiments were antigen specific, we expected that as in the BP model, changes in total PF and PV IgG levels versus Dsg1- and Dsg3-specific IgG levels should be the same.

This hypothesis also predicts that HDIG will no longer inhibit the disease activity when the pathogenic antibodies are used at higher levels than the threshold level for the disease development. To prove this, mice were pretreated with IgM control ( $6.47 \mathrm{mg} / \mathrm{g}$ body weight) or HDIG (1 mg/g body weight), injected with different doses of pathogenic anti-mBP180 antibodies $(25,50,100$, and $200 \mu \mathrm{g} / \mathrm{g}$ body weight), and examined clinically at 48 hours. A dose of $1 \mathrm{mg} / \mathrm{g}$ body weight of HDIG completely abolished BP disease in mice injected with $25 \mu \mathrm{g} / \mathrm{g}$ body weight of anti-mBP180 antibody. As pathogenic antibody levels were increased, the inhibition activity of the $1 \mathrm{mg}$ HDIG was gradually diminished: the disease activities in the IgM- versus HDIG-treated mice were $2.92 \pm 0.08$ versus $1.25 \pm 0.11$ $(50 \mu \mathrm{g} ; P<0.0001), 3 \pm 0.00$ versus $2.83 \pm 0.11(100 \mu \mathrm{g} ; P=0.14)$, and $3 \pm 0.00$ versus $3 \pm 0.00(200 \mu \mathrm{g} ; P=1.00)$.

$F c R n$-deficient mice are resistant to experimental $B P, P F$, and $P V$. If the function of HDIG is to increase pathogenic antibody degradation, then mice deficient in FcRn should phenocopy HDIG-treated WT mice. Our next set of experiments proved this is the case. As shown previously (66), pathogenic anti-mBP180 IgG (25 $\mu \mathrm{g} / \mathrm{g}$ body weight) induced BP disease in WT (Figure 3, A and C) but not $\mathrm{FcRn}^{-/-}$mice (Figure 3, D and F). The non-diseased $\mathrm{FcRn}^{-/-}$mice showed significantly reduced levels of neutrophil recruitment in the skin (Figure $3 \mathrm{G}$ ) and pathogenic IgG in circulation (Figure $3 \mathrm{H}$ ) as compared with the diseased mice ( $n=9$ for each group). Total rabbit IgG levels were also significantly reduced in the $\mathrm{FcRn}^{-/}$mice (2.09 \pm 0.31 down to $0.86 \pm 0.10 ; P<0.001)$. The reduced IgG level in the circulation also led to a marked reduction in in situ deposition of anti-mBP180 IgG at the basement membrane, as assayed by direct immunofluorescence (IF) (Figure 3, B vs. E). Similarly, pathogenic anti-Dsg1 (Figure 4, A-C) and anti-Dsg3 (Figure 4, D-F) IgG failed to trigger PF and PV skin lesions in $\mathrm{FcRn}^{-/}$- mice $(n=6)$, respectively, with significantly reduced 


\section{Table 2}

Relative contribution of FcRn and FcyRll pathways to experimental pemphigus and pemphigoidA

\begin{tabular}{|c|c|c|c|c|}
\hline $\begin{array}{l}\text { Mouse } \\
\text { strain }\end{array}$ & Antibody & $\begin{array}{c}\text { No. of } \\
\text { mice }\end{array}$ & $\begin{array}{c}\text { Clinical } \\
\text { disease score } \\
\text { (mean } \pm \text { SEM) }\end{array}$ & $\begin{array}{c}P \\
\text { value }\end{array}$ \\
\hline \multirow[t]{3}{*}{ WT } & Anti-mBP180 & 6 & $1.67 \pm 0.11$ & - \\
\hline & Anti-mBP180 + IgM & 6 & $1.75 \pm 0.27$ & 0.5994 \\
\hline & Anti-mBP180 + HDIG & 6 & $0.00 \pm 0.00$ & 0.0001 \\
\hline \multirow[t]{4}{*}{$\mathrm{FcRn} n^{-/-}$} & Anti-mBP180 & 6 & $0.08 \pm 0.08$ & 0.0001 \\
\hline & Anti-mBP180 + IgM & 6 & $0.00 \pm 0.00$ & 0.0001 \\
\hline & Anti-mBP180 + HDIG & 6 & $0.00 \pm 0.00$ & 0.0001 \\
\hline & Anti-mBP180 (i.d.) + HDIG & 6 & $2.08 \pm 0.15$ & 0.0493 \\
\hline \multirow[t]{3}{*}{$\mathrm{F} c \gamma \mathrm{RII}-/-$} & Anti-mBP180 & 6 & $1.83 \pm 0.11$ & 0.3632 \\
\hline & Anti-mBP180 + IgM & 6 & $1.75 \pm 0.11$ & 0.5995 \\
\hline & Anti-mBP180 + HDIG & 6 & $0.17 \pm 0.11$ & 0.0004 \\
\hline \multirow[t]{3}{*}{ WT } & Anti-Dsg1 & 6 & $1.50 \pm 0.13$ & - \\
\hline & Anti-Dsg1 + IgM & 6 & $1.83 \pm 0.11$ & 0.0734 \\
\hline & Anti-Dsg1 + HDIG & 6 & $0.00 \pm 0.00$ & 0.0001 \\
\hline \multirow[t]{4}{*}{$\mathrm{FcRn}^{-/-}$} & Anti-Dsg1 & 6 & $0.08 \pm 0.08$ & 0.0003 \\
\hline & Anti-Dsg1 + IgM & 6 & $0.00 \pm 0.00$ & 0.0001 \\
\hline & Anti-Dsg1 + HDIG & 6 & $0.08 \pm 0.08$ & 0.0001 \\
\hline & Anti-Dsg1 (i.d.) + HDIG & 6 & $1.75 \pm 0.11$ & 0.1739 \\
\hline \multirow[t]{3}{*}{$\mathrm{Fc} \gamma \mathrm{RII}^{-/-}$} & Anti-Dsg1 & 6 & $1.42 \pm 0.13$ & 0.6951 \\
\hline & Anti-Dsg1 + IgM & 6 & $1.42 \pm 0.15$ & 0.6867 \\
\hline & Anti-Dsg1 + HDIG & 6 & $0.17 \pm 0.11$ & 0.0005 \\
\hline \multirow[t]{3}{*}{ WT } & Anti-Dsg3 & 6 & $1.58 \pm 0.15$ & - \\
\hline & Anti-Dsg3 + IgM & 6 & $1.75 \pm 0.17$ & 0.4848 \\
\hline & Anti-Dsg3 + HDIG & 6 & $0.08 \pm 0.08$ & 0.0001 \\
\hline \multirow[t]{4}{*}{$\mathrm{FcRn}^{-/-}$} & Anti-Dsg3 & 6 & $0.08 \pm 0.08$ & 0.0004 \\
\hline & Anti-Dsg3 + IgM & 6 & $0.08 \pm 0.08$ & 0.0001 \\
\hline & Anti-Dsg3 + HDIG & 6 & $0.08 \pm 0.08$ & 0.0001 \\
\hline & Anti-Dsg3 (i.d.) + HDIG & 6 & $1.83 \pm 0.11$ & 0.2094 \\
\hline \multirow{3}{*}{$\mathrm{Fc} \gamma \mathrm{RII}-{ }^{--}$} & Anti-Dsg3 & 6 & $1.50 \pm 0.13$ & 0.7412 \\
\hline & Anti-Dsg3 + IgM & 6 & $1.75 \pm 0.21$ & 0.5413 \\
\hline & Anti-Dsg3 + HDIG & 6 & $0.00 \pm 0.00$ & 0.0001 \\
\hline
\end{tabular}

ANeonatal mice were pretreated with buffer, IgM control $(6.47 \mathrm{mg} / \mathrm{g}$ body weight), or HDIG (1 mg/g body weight) and 2 hours later injected i.p. with optimal dose of antigen-specific column-purified anti-mBP180 (25 $\mu \mathrm{g} / \mathrm{g}$ body weight), anti-Dsg1 (PF1, $40 \mu \mathrm{g} / \mathrm{g}$ body weight), or antiDsg3 lgG (50 $\mu \mathrm{g} / \mathrm{g}$ body weight). Injected animals were examined clinically 48 hours after pathogenic IgG injection, and clinical disease activity was scored and averaged in each group and expressed as mean disease score \pm SEM (see Methods for more details). $P$ values between positive control group and deficient mouse groups were calculated by paired Student's $t$ test. A $P$ value less than 0.05 was considered significant. i.d., intradermal.

levels of pathogenic antibody in circulation. These data show that FcRn deficiency and HDIG treatment lead to the same degree of accelerated degradation of pathogenic IgG.

Increased pathogenic IgG degradation by HDIG is mediated by FcRn. If HDIG acts on FcRn to accelerate pathogenic IgG degradation, then HDIG will not effect pathogenic IgG degradation in $\mathrm{FcRn}^{-/-}$mice. To test this, we injected pathogenic IgG i.p. into FcRn-deficient mice pretreated with IgM control or HDIG and monitored circulating pathogenic IgG levels at different time points (6-48 hours). As expected, WT mice injected with pathogenic anti-mBP180 IgG $(25 \mu \mathrm{g} / \mathrm{g}$ body weight) without HDIG pretreatment maintained high levels of circulating pathogenic IgG across all time points and developed subepidermal blisters at 24 and 48 hours (Figure 5A). In contrast, $\mathrm{FcRn}^{-/}$mice injected with pathogenic anti-mBP180 IgG and
WT mice coinjected with pathogenic IgG and HDIG $(1 \mathrm{mg} / \mathrm{g}$ body weight) exhibited a significant reduction in circulating pathogenic IgG and failed to developed BP lesions (Figure 5A). However, administration of the same dose or a 2-fold higher dose of HDIG failed to induce further degradation of pathogenic IgG in FcRn-deficient mice compared with FcRn-deficient mice without HDIG treatment (Figure 5A). Similar patterns were also observed in experimental PF and PV: HDIG failed to increase the clearance of anti-Dsg1 and antiDsg3 IgG in FcRn- ${ }^{-/}$mice (Figure 5, B and C). The ability of HDIG but not IgM to promote the clearance of pathogenic IgG in WT but not $\mathrm{FcRn}^{-/}$mice and to mirror the clearance observed in $\mathrm{FcRn}^{-/-}$ mice is consistent with HDIG recapitulating the $\mathrm{FcRn}^{-/}$phenotype by saturating the $\mathrm{FcRn}$ protection pathway.

We also determined whether HDIG offered some additional effect when $\mathrm{FcRn}^{-/-}$mice were injected with higher doses of pathogenic IgG. $\mathrm{FcRn}^{-/}$mice were pretreated with buffer, control IgM, or HDIG and 2 hours later were injected i.p. with 2- and 4-fold more pathogenic anti-mBP180 (50 and $100 \mu \mathrm{g} / \mathrm{g}$ body weight), anti-Dsg1 (80 and $160 \mu \mathrm{g} / \mathrm{g}$ body weight), or anti-Dsg3 (100 and $200 \mu \mathrm{g} / \mathrm{g}$ body weight) IgG. The mice were examined 48 hours after pathogenic IgG injection. As expected, the mice developed skin lesions in a dose-dependent fashion (Figure 6, A and B). Higher doses of pathogenic IgG caused more severe clinical blistering. However, there was no statistically significant difference in pathogenic IgG levels between $\mathrm{FcRn}^{-/}$mice with and without HDIG pretreatment at these pathogenic IgG doses (Figure 6, A and B). Higher doses of pathogenic IgG resulted in lower IgG degradation rates (Figure 6, C-E). These results suggest that $\mathrm{F} C R n$ is required in order for HDIG to promote the clearance of pathogenic IgG.

FcRn deficiency and HDIG treatment do not interfere with the direct binding of pathogenic IgG to its target. To determine whether the lack of FcRn and HDIG treatment interferes with pathogenic IgG binding to its target that leads to inhibition of blistering, pathogenic IgG was mixed with buffer control, IgM control, or HDIG at final concentrations similar to or higher than the therapeutic serum level of HDIG in the mouse model (pathogenic IgG/HDIG or IgG/IgM were mixed at a 1:25 molar ratio). The preabsorbed pathogenic IgG was then tested for antigen binding and pathogenic activities. In vitro, we stained skin sections from WT and $\mathrm{FcRn}^{-/}$mice with serial dilutions up to the detection limits for the positive samples without HDIG preabsorption (anti-mBP180, 1:1,000 to 1:8,000 dilutions; anti-Dsg1, 1:200 to 1:800 dilutions; and anti-Dsg3, 1:200 to 1:800 dilutions). There was no detectable difference in indirect IF staining density between WT and $\mathrm{FcRn}^{-/}$skin sections and no detectable difference in staining density with and without HDIG coincubation (Figure 7, A-C).

In vivo, WT and $\mathrm{FcRn}^{-/-}$mice injected intradermally with pathogenic anti-mBP180, anti-Dsg1, or anti-Dsg3 IgG preabsorbed with buffer, IgM, or HDIG developed clinical BP, PF, and PV, respectively (Figure 7D and Table 2). As expected, the disease activity in WT mice injected with HDIG-preabsorbed pathogenic antibody was very similar to that in WT mice injected with buffer- or IgM-preabsorbed pathogenic antibody. Pathogenic IgG levels in WT mice injected with HDIG-preabsorbed pathogenic antibody were lower than in WT mice injected with IgM-preabsorbed pathogenic antibody (Figure 7E). There was no difference in clinical disease scores and serum IgG levels between WT mice injected with buffer- and IgMpreabsorbed pathogenic antibody (Figure 7, D and E). $\mathrm{FcRn}^{-/}$mice injected with buffer-, IgM- and HDIG-preabsorbed pathogenic IgG had compatible levels of circulating pathogenic IgG and developed clinical blisters to the same degree (Table 2). Similar results were 

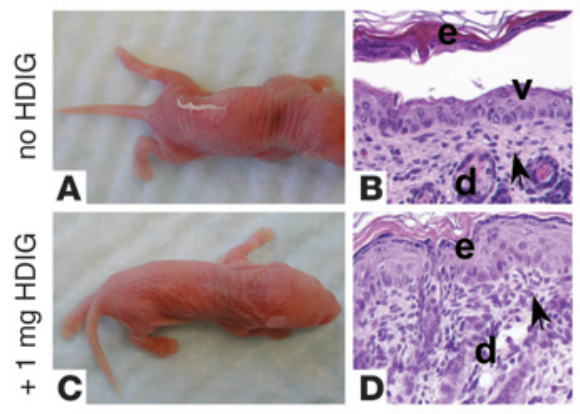

E
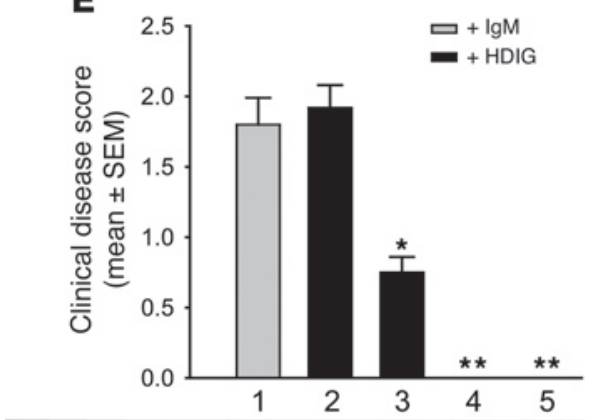

\begin{tabular}{c|ccccc}
\hline HDIG dose $(\mathrm{mg})$ & 0 & 0 & 0.5 & 1.0 & 2.0 \\
\hline \% anti-Dsg1 level & 93.8 & 100 & 61.8 & 43.2 & 38.7
\end{tabular}
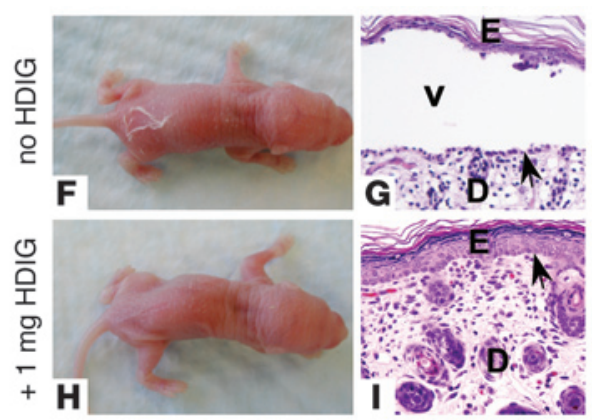

J

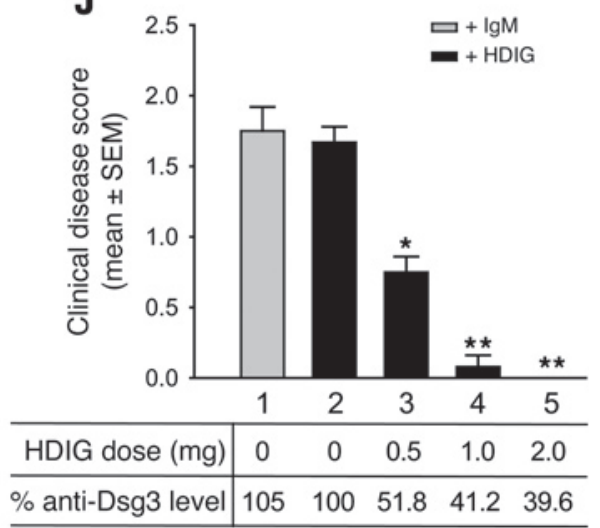

Figure 2

HDIG inhibits experimental PF and PV by accelerating degradation of pathogenic human autoantibody IgG. Neonatal C57BL/6J mice were pretreated with buffer, IgM (12.93 mg/g body weight), or different doses of HDIG (0-2 mg/g body weight) and injected i.p. with pathogenic anti-Dsg1 IgG (PF1, $40 \mu \mathrm{g} / \mathrm{g}$ body weight) or anti-Dsg3 IgG (PV1, $50 \mu \mathrm{g} / \mathrm{g}$ body weight) 2 hours later. The animals were examined 48 hours after pathogenic IgG injection. Mice without HDIG treatment developed subcorneal PF blisters (A and B), while $1 \mathrm{mg} \mathrm{HDIG}$ completely blocked skin lesions (C and D). (E) HDIG treatment resulted in significant reduction in clinical disease scores and levels of circulating anti-Dsg1 lgG (bars 3-5) as compared with control (bars 1 and 2). Mice without HDIG treatment developed suprabasal PV blisters ( $\mathbf{F}$ and $\mathbf{G}$ ), while $1 \mathrm{mg}$ HDIG completely blocked skin lesions (H and I). (J) HDIG treatment resulted in significant reduction in clinical disease scores and levels of circulating anti-Dsg3 IgG (bars 3-5) relative to control (bars 1 and 2$) . n=8 .{ }^{\star} P<0.05 ;{ }^{\star \star} P<0.001$. Arrows indicate basal keratinocytes. seen in mice injected i.p. with HDIG first followed by intradermal injection of pathogenic antibody (data not shown). These results demonstrate that the HDIG preparation used in this study does not contain antibodies that inhibit binding of pathogenic anti-BP180, anti-Dsg1, and anti-Dsg3 to respective target antigens in skin.
Fc R RIIb is not required for the antiinflammatory activity of HDIG and does not ameliorate skin lesions in experimental $B P, P F$, and $P V$. The inhibitory Fc $\gamma$ RII receptor is considered to be a target for IVIG action in the autoimmune ITP and $\mathrm{K} / \mathrm{BxN}$ arthritis models (48-50). To assess the contribution of FcyRII to HDIG activity in our pemphigus and pem-
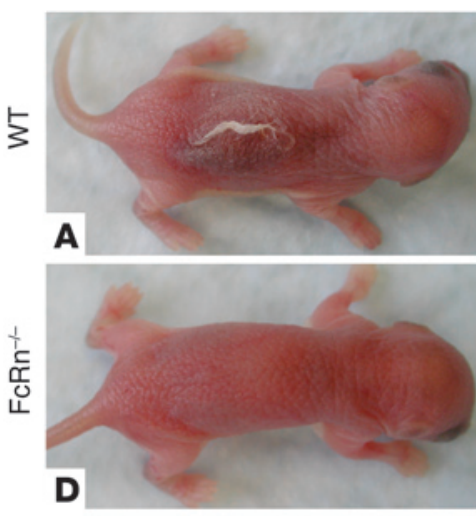

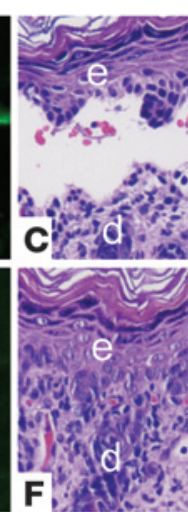

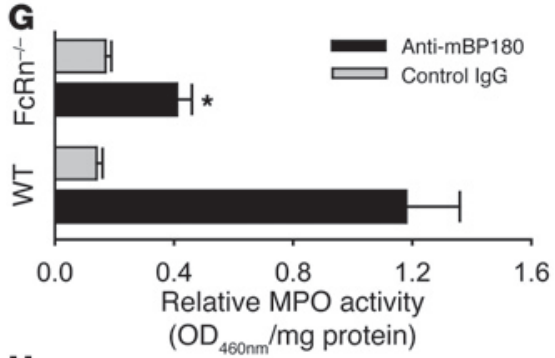

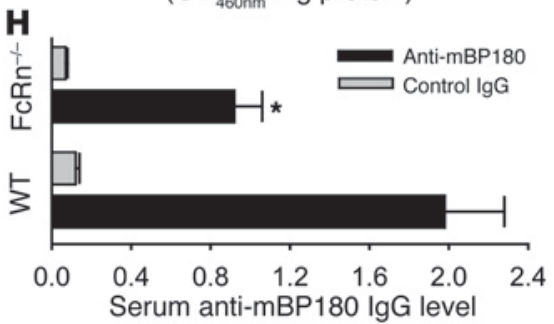

(relative $O D$ reading)

Figure 3

FcRn-deficient mice are resistant to experimental BP. Neonatal WT and FcRn ${ }^{-1}$ mice were injected i.p. with pathogenic anti-mBP180 IgG or normal rabbit lgG control ( $25 \mu \mathrm{g} / \mathrm{g}$ body weight) and examined 48 hours after injection. WT mice receiving pathogenic IgG developed clinical (A) and histological (C) evidence of subepidermal blisters. Direct IF exhibited in vivo deposition of rabbit anti-mBP180 IgG at the basement membrane (B). In contrast, $\mathrm{FCRn}^{-1-}$ mice showed no skin lesions ( $\mathbf{D}$ and $\mathbf{F}$ ) and very weak IgG deposition at the basement membrane (E). (G) The MPO assay showed a significant reduction in neutrophil infiltration in $\mathrm{FcRn}^{-/}$mice relative to WT mice. (H) ELISA assay revealed a significant acceleration of pathogenic IgG degradation in FcRn-l- mice. $n=6$. ${ }^{\star} P<0.01$. Arrow indicates site of pathogenic antibody binding. 


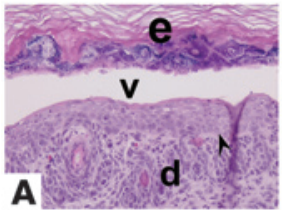

WT

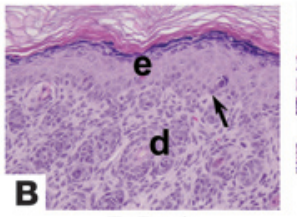

$\mathrm{FcRn}^{-1-}$

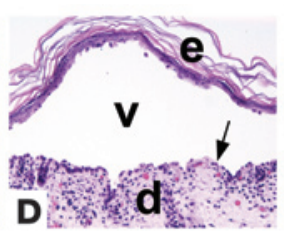

WT

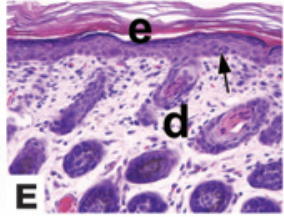

$\mathrm{FCRn}^{-1-}$
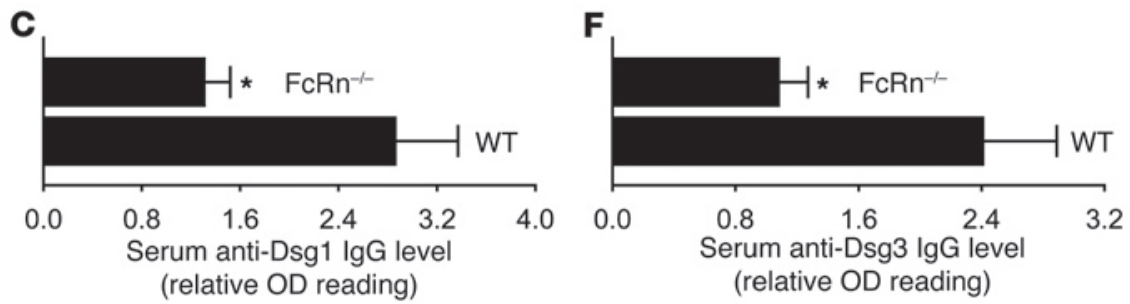

\section{Figure 4}

FcRn-deficient mice are resistant to experimental PF and PV. Neonatal WT and FcRn ${ }^{-1-}$ mice were injected i.p. with pathogenic anti-Dsg1 (PF1, $40 \mu \mathrm{g} / \mathrm{g}$ body weight) (A-C) or anti-Dsg3 (PV1, $50 \mu \mathrm{g} / \mathrm{g}$ body weight) (D-F) IgG and examined 48 hours after injection. (A-C) PF model. WT mice receiving pathogenic IgG developed subcorneal blisters (A), while $\mathrm{FcRn}^{-/}$mice showed no skin lesions (B). (C) ELISA revealed a significant reduction in circulating anti-Dsg1 IgG levels in $\mathrm{FcRn}^{-/}$as compared with WT mice. (D-F) PV model. WT mice receiving pathogenic IgG developed suprabasal blisters (D), while $\mathrm{FCRn}^{-/}$mice showed no skin lesions (E). (F) ELISA revealed a significant reduction in circulating anti-Dsg3 lgG levels in $\mathrm{FcRn}^{-/}$as compared with WT mice. $n=8$. ${ }^{*} P<0.01$. Arrow indicates basal keratinocytes. phigoid models, we injected WT and $\mathrm{Fc} \gamma \mathrm{RII}^{-/-}$mice with pathogenic anti-mBP180, anti-Dsg1, and anti-Dsg3 antibodies in the presence or absence of HDIG treatment. At 48 hours after injection, these mice were examined clinically, and levels of circulating pathogenic antibodies were quantified by ELISA. Fc $\gamma \mathrm{RII}^{-/}$- mice injected with pathogenic IgG developed a similar intensity of skin lesions compared with diseased WT mice, and there was no difference in levels of pathogenic IgG between these 2 groups (Figure 8 and Table 2). HDIG treatments ( $1 \mathrm{mg} / \mathrm{g}$ body weight) but not IgM control blocked skin blistering and caused a very similar degree of reduction in pathogenic IgG levels in the circulation in WT and $\mathrm{Fc} \gamma \mathrm{RII}^{-/-}$mice (Figure 8). These results demonstrate that the antiinflammatory activity of HDIG in the BP, PF, and PV mouse models, under the experimental conditions used, is not dependent on FcyRII.

\section{Discussion}

Despite its increasing applications in the treatment of immune-mediated inflammatory diseases, the mechanism(s) of IVIG action remain unclear. Using IgG passive transfer models of autoimmune blistering diseases pemphigus and pemphigoid, we show that FcRn is absolutely required to realize a benefit from HDIG therapy. Our data show that (a) mice deficient in FcRn are resistant to experimental pemphigus and pemphigoid and show a substantial reduction in circulating pathogenic IgG antibodies; (b) similar to an FcRn deficiency, HDIG treatment causes accelerated clearance of pathogenic antibody and abolishes skin lesions; (c) HDIG treatment of FcRndeficient mice fails to cause a further lowering of pathogenic antibody. These results are in agreement with findings in ITP and serum-induced arthritis models, all suggesting that a high dose of IVIG saturates FcRn binding sites and hence pathogenic

\section{Figure 5}
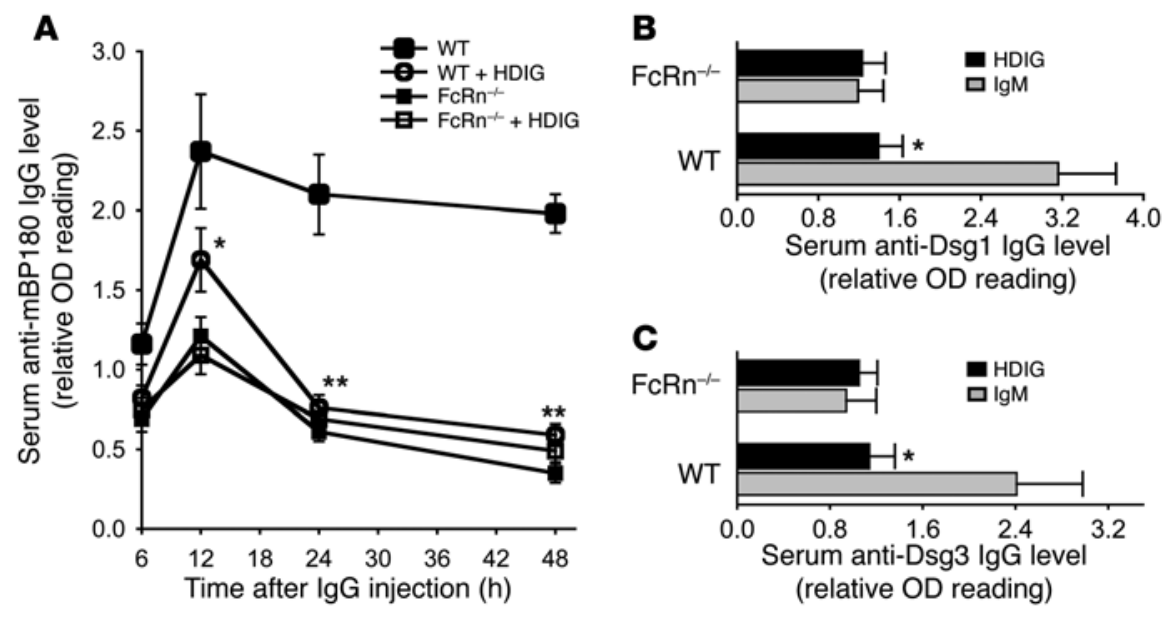

No further degradation of pathogenic IgG by HDIG in FcRn-deficient mice. WT and FcRn ${ }^{-/}$mice were pretreated with buffer control, IgM control $(6.47 \mathrm{mg} / \mathrm{g}$ body weight), or HDIG (1 mg/g body weight) and then injected i.p. with pathogenic anti-BP180 lgG ( $25 \mu \mathrm{g} / \mathrm{g}$ body weight), anti-Dsg1 IgG (PF1, $40 \mu \mathrm{g} / \mathrm{g}$ body weight), or anti-Dsg3 IgG (50 $\mu \mathrm{g} / \mathrm{g}$ body weight). Pathogenic IgG levels in circulation at different time points after pathogenic IgG injection were quantified by ELISA. (A) BP model. Significantly higher levels of circulating anti-BP180 IgG were present in WT mice without HDIG treatment than WT mice with HDIG treatment at 12,24 , and 48 hours. In contrast to WT mice, FcRn-deficient mice with and without HDIG treatment showed similar levels of circulating anti-BP180 IgG. IgM pretreatment had no effect on the serum anti-mBP180 lgG levels at all time points examined $\left(1.04 \pm 0.11,2.47 \pm 0.34,2.09 \pm 0.32\right.$, and $2.16 \pm 0.29 O_{492 n m}$ reading units at 6, 12, 24, and 48 hours, respectively). (B) PF model. HDIG treatment resulted in significantly reduced levels of anti-Dsg1 IgG in WT mice but not in $\mathrm{FcRn}^{-1-}$ mice 48 hours after injection as compared with control IgM-treated WT mice. (C) PV model. As in the PF model, HDIG caused a significant reduction in circulating anti-Dsg3 IgG levels in WT but not in $\mathrm{FcRn}^{-1}$ mice 48 hours after injection. These data show that increased degradation of pathogenic IgG is mainly dependent upon the FcRn-mediated pathway. $n=6$. ${ }^{\star} P<0.05 ;{ }^{* \star} P<0.001$. 


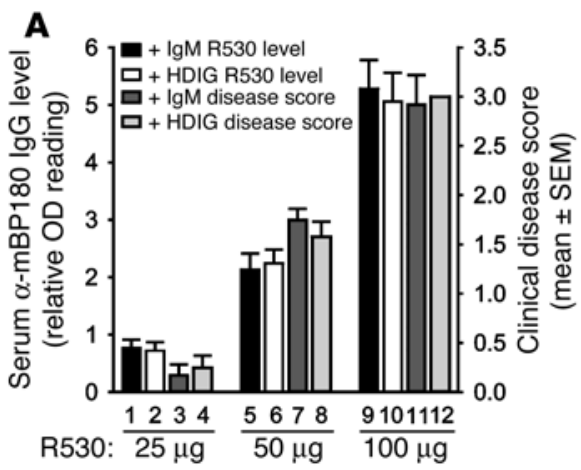

\section{B}

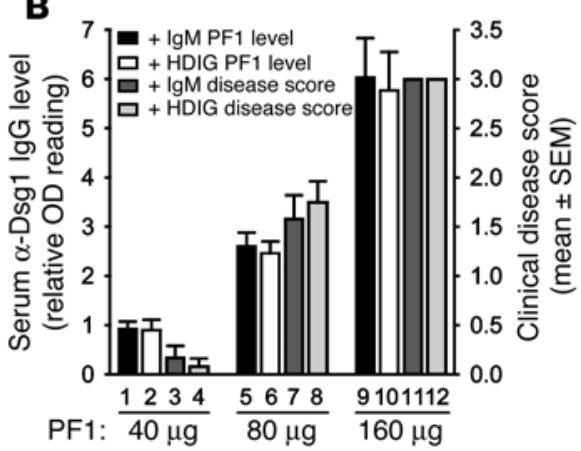

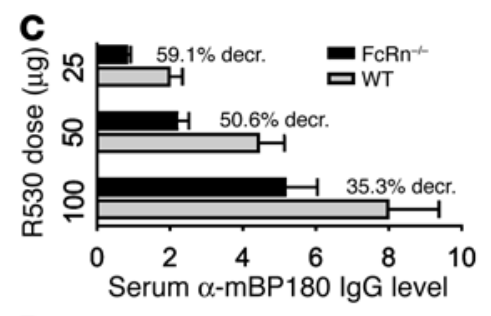
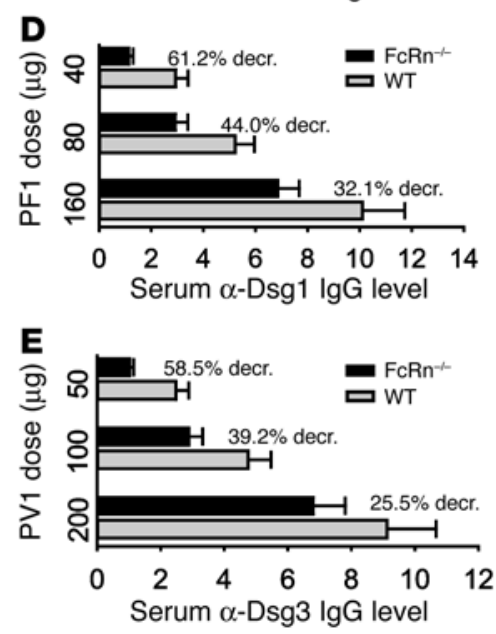

\section{Figure 6}

Relationship among pathogenic IgG doses, IgG clearance rate, and disease activity in FcRndeficient mice. (A and B) $\mathrm{FcRn}^{-1-}$ mice were pretreated with IgM $(6.47 \mathrm{mg} / \mathrm{g}$ body weight) or HDIG (1 mg/g body weight) and 2 hours later injected i.p. with different doses of anti-mBP180 R530, anti-Dsg1 (PF1), or anti-Dsg3 (PV1). The mice were examined 48 hours after pathogenic IgG injection. Serum anti-mBP180 lgG levels in mice pretreated with IgM (black bars) or HDIG (white bars) were quantified by ELISA. Disease activities in mice pretreated with IgM (dark gray bars) or HDIG (light gray bars) were scored by clinical examination. As expected, higher doses of anti-mBP180 lgG (A), anti-Dsg1 lgG (B), and anti-Dsg3 IgG (data not shown) caused higher levels of pathogenic IgG in circulation and more severe clinical diseases. There was no difference in IgG levels and disease severity between IgM- and HDIG-treated mice at each dose of pathogenic IgG. (C-E) WT and $\mathrm{FCRn}^{-1-}$ mice were injected i.p. with different doses of pathogenic IgG, and serum pathogenic IgG levels were assayed by ELISA 48 hours later. $59.1 \%$, $50.6 \%$, and $35.3 \%$ decreases (decr.) in anti-mBP1 80 lgG levels were seen in $\mathrm{FcRn}^{-1-}$ compared with WT mice at 25, 50, and 100 doses, respectively (C). Similarly, higher doses of anti-Dsg1 and anti-Dsg3 IgG led to lower rates of IgG degradation (D and $\mathbf{E}) . n=6$.

(8). Subepidermal blistering in BP is induced by pathogenic antiBP180 IgG and depends on complement activation, mast cell degranulation, and neutrophil infiltration (18-20). However, HDIG treatment led to a similar degree of reduction in circulating pathogenic antibodies in all 3 blistering disease models regardless of their disease mechanisms. These findings should be directly beneficial to other human blistering diseases in which IgG autoantibodies target Dsg3 and BP180, including paraneoplastic pemphigus (anti-Dsg3) (67), mucous membrane pemphigoid, pemphigoid gestationis, lichen planus pemphigoides (anti-BP180) (68-70).

The ratio of HDIG to anti-mBP180 IgG in mice was $1 \mathrm{mg} \mathrm{HDIG} / \mathrm{g}$ body weight versus 1:1,280 anti-mBP180 IgG titer. In PF and PV mice, the HDIG/anti-Dsg1 or HDIG/anti-Dsg3 IgG ratio was $1 \mathrm{mg}$ HDIG/g body weight versus 1:640 anti-Dsg1 or anti-Dsg3 IgG titer. In IVIG-treated patients (BP, PF, and PV), the IVIG/patients' autoantibody ratio is approximately $0.7 \mathrm{~g}$ IVIG/ $\mathrm{kg}$ body weight/day/3-day cycle versus $1: 160$ (1:40 to 1:640 for most patients' sera) autoantibody titers (34). The ratio of IVIG levels/autoantibody levels in the serum of treated patients is compatible with that of the treated mice.
However, mice received only 1 dose of pathogenic IgG, while pathogenic autoantibodies are constantly synthesized in patients. Therefore, higher levels (higher dose and/or multiple doses) of IVIG should be recommended for treating these patients. Our findings also suggest that IVIG will only work through FcRn in patients with antibody concentrations below that which results in FcRn saturation, as suggested in the arthritis model (50).

The extent to which the therapeutic benefits of HDIG in the autoimmune blistering disease PF, PV, and BP models are dependent on FCRn is intriguing. We ruled out the possibility that HDIG used in our study contains antiidiotypic antibodies that neutralize anti-Dsg1, anti-Dsg3, and anti-BP180 IgG because up to a 25-fold excess HDIG still shows no blocking of pathogenic antibody binding to the respective targets in the skin and inducing skin lesions (Figure 7). In experimental immune ITP and in the $\mathrm{K} / \mathrm{BxN}$ murine model of autoimmune arthritis, IVIG has been shown to act through both the FcRn saturation and the FcyRII inhibitory pathways (48-50). Recent studies performed using the ITP and $\mathrm{K} / \mathrm{BxN}$ serum transfer models have additionally shown an Fc $\gamma$ RII-dependent pathway in which natural autoantibodies forming soluble antigen antibody complexes are antiinflammatory (71). However, in experimental antiphospholipid antibody syndrome, IVIG ameliorates the disease in a manner inconsistent with proinflammatory Fc $\gamma \mathrm{R}$ involvement, possibly by FcRn saturation, but a role for Fc $\gamma$ RII has not been formally excluded (45). Our findings suggest that FcRn saturation is a dominant mechanism for the action of HDIG in the pemphigus and pemphigoid models. While various mechanisms could operate additively or synergistically depending on the modeled disease, the common, emerging theme is that the FcRn saturation pathway is invoked by HDIG in all autoimmune models induced by pathogenic IgG antibodies analyzed to date. This is logical, as FcRn controls the availability of autoantibodies available for whatever downstream events mediate the particular disease's pathological processes.

It is also of interest that $\mathrm{Fc} \gamma \mathrm{RIIb}^{-/-}$mice showed the same degree of the BP disease as did the WT mice (Table 2). The inhibitory IgG receptor Fc $\gamma \mathrm{RIIb}$ is expressed on leukocytes including B cells, macrophages, neutrophils, and mast cells and downregulates functions of the activating IgG receptors Fc $\gamma \mathrm{RI}$ and -RIII. Mice deficient in Fc $\gamma$ RIIb develop more severe autoimmune diseases, such as ITP, glomerulonephritis, arthritis, and lupus (51-54). Neutrophils and mast cells are absolutely required for subepidermal blistering in experimental BP $(19,20)$, Our findings that mice deficient in Fc $\gamma$ RIIb fail to develop more intense skin lesions is therefore inconsistent with a normal antiinflammatory role for Fc $\gamma$ RIIb in this disease.

In summary, the HDIG activity in the treatment of IgG antibody-induced pemphigus and pemphigoid in mice is mainly dependent on FcRn. Overall, IVIG is not an ideal antiautoim- 


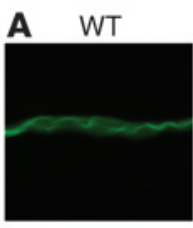

$-$

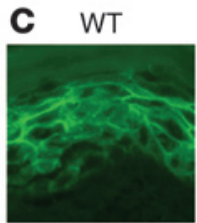

D

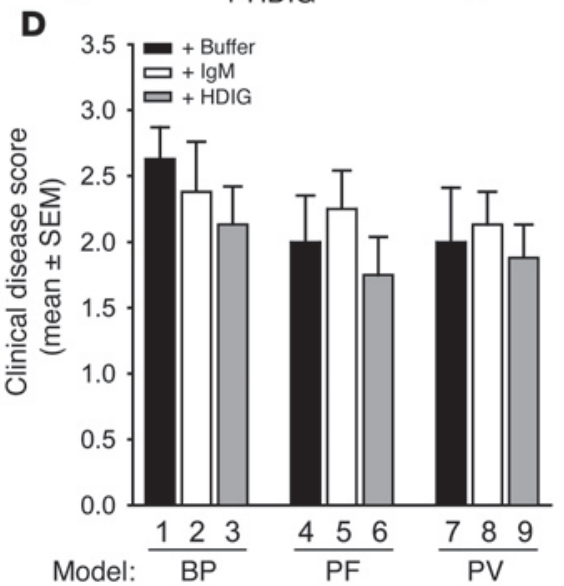

WT

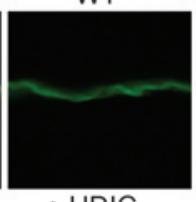

+ HDIG

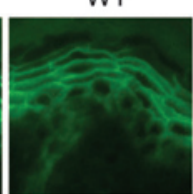

$+\mathrm{HDIG}$

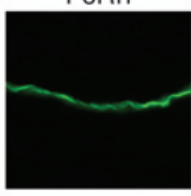

$-$

\section{$\mathrm{FCRn}^{-1-}$}

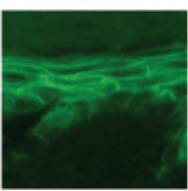

$-$

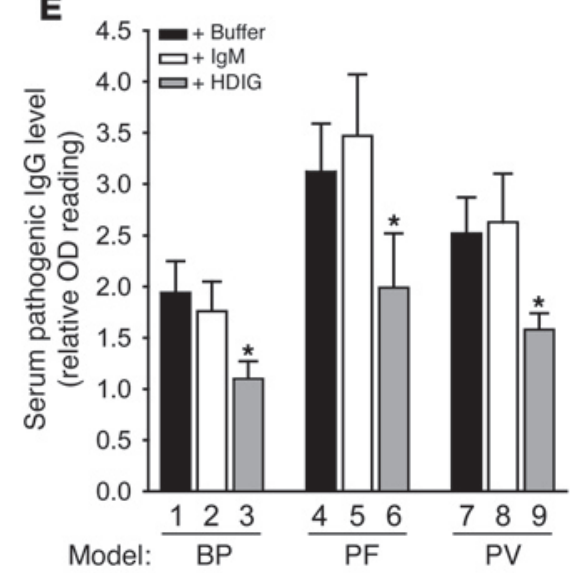

Figure 7

HDIG does not directly inhibit activities of pathogenic IgG. Pathogenic lgG (1 mg/ml R530, anti-Dsg1 from PF1, or anti-Dsg3 from PV1) was incubated with buffer control, IgM, or HDIG $(25 \mathrm{mg} / \mathrm{ml})$ at room temperature for 1 hour. (A) Supernatants containing anti-mBP180 IgG coincubated with buffer or HDIG showed the same IF staining density at the basement membrane zone. Supernatants containing anti-Dsg1 (B) or anti-Dsg3 (C) IgG coincubated with buffer or HDIG showed the same IF staining density at the keratinocyte cell surface. Supernatants with IgM preabsorption showed the same IF density (data not shown). (D) Supernatants containing anti-mBP180 (equivalent to $25 \mu \mathrm{g} / \mathrm{g}$ body weight), anti-Dsg1 (equivalent to $40 \mu \mathrm{g} / \mathrm{g}$ body weight), or anti-Dsg3 (equivalent to $50 \mu \mathrm{g} / \mathrm{g}$ body weight) preabsorbed with buffer (bars 1,3 , and 7), IgM (bars 2,5 , and 8 ), or HDIG (bars 3, 6, and 9), when injected intradermally into WT or FcRn-1- mice (Table 2), induced BP (bars 1-3), PF (bars 4-6), and PV (bars 7-9) clinical blisters, respectively, 48 hours after pathogenic IgG administration. (E). ELISA revealed similar levels of serum pathogenic anti-mBP180 (bars 1 and 2), anti-Dsg1 (bars 4 and 5), and anti-Dsg3 (bars 7 and 8) in mice injected with supernatants preabsorbed with buffer (bars 1, 4, and 7) and IgM (bars 2, 5, and 8). As expected, serum levels of pathogenic IgG were reduced in mice injected with supernatants preabsorbed with HDIG (bars 3,6 , and 9). $n=6 .{ }^{*} P<0.01$.

mune therapeutic because of its expense, extended course of delivery, and side effects. It is thus usually reserved for patients that are nonresponsive to other therapies. Selective blockade of $\mathrm{FcRn}$ is, therefore, a promising generic therapeutic strategy.

\section{Methods}

Animals. Breeding pairs of $\mathrm{FcRn}-/-$ mice on a C57BL/6J background (65) and WT C57BL/6J mice were obtained from the Jackson Laboratory. $\mathrm{Fc}_{\mathrm{RIIb}} \mathrm{R}^{--}$mice on a C57BL/6J background were obtained from Taconic. The animals were bred at the University of North Carolina at Chapel Hill Animal Resource Center. Neonatal mice (36-48 hours old with body weights between 1.5 and $1.8 \mathrm{~g}$ ) were used for passive transfer experiments. Animal care and animal experiments were approved by the Animal Care Committee at the University of North Carolina at Chapel Hill and were in accordance with NIH guidelines.

Affinity-purification of pathogenic anti-Dsg1, anti-Dsg3, and anti-BP180 IgG. Anti-Dsg1 and anti-Dsg3 autoantibodies were affinity-purified from PF $(n=2, \mathrm{PF} 1$ and PF2) and PV ( $n=2, \mathrm{PV} 1$ and PV2) patients, respectively, using the entire extracellular domain of Dsg1 and Dsg3 produced by the baculovirus system immobilized with Ni-NTA columns (QIAGEN) (72). The preparation of recombinant $\mathrm{mBP} 180$ and the immunization of rabbits were performed as previously described (14). Briefly, a segment of the mBP180 antigen containing the pathogenic epitope was expressed, purified to homogeneity by affinity chromatography, and used to immunize New Zealand White rabbits. The IgG fraction from the sera (referred to as R530) was isolated as previously described (17), and pathogenic anti-mBP180 IgG was further purified using the recombinant $\mathrm{mBP} 180$ fragment containing pathogenic epitope (73) immobilized in an agarose affinity column. The titer of purified antibodies was assayed by indirect IF using mouse skin cryosections as substrate (17). The pathogenicity of the purified IgG was tested by passive transfer experiments as described below.

Induction of experimental BP, PF, and PV. A 50- $\mu$ l dose of sterile IgG in PBS was administered to neonatal mice by i.p. injection $(0-100 \mu \mathrm{g} \mathrm{IgG} / \mathrm{g}$ body weight). The skin of neonatal mice from the test and control groups was examined at 24 and 48 hours after the IgG injection. The extent of cutaneous disease for IgG passive transfer BP was scored as follows: -, no detectable skin 


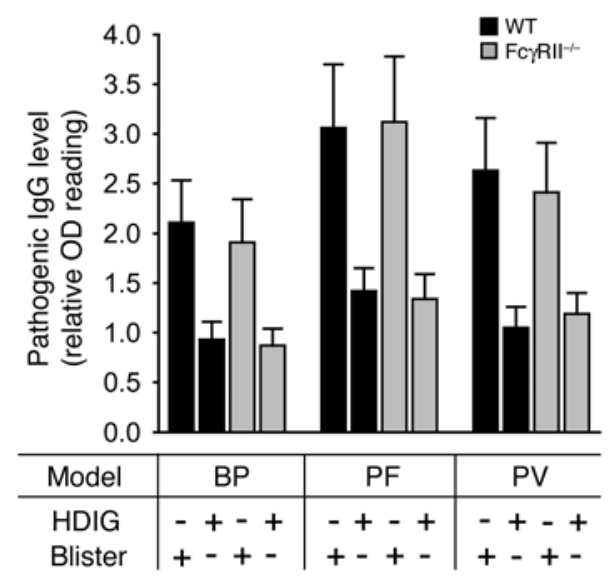

Figure 8

Contribution of $\mathrm{Fc} \gamma \mathrm{RII}$ to HDIG-induced degradation of pathogenic IgG. WT and $\mathrm{Fc}_{\gamma} \mathrm{RII}^{-1-}$ mice were injected i.p. with pathogenic anti-BP180 ( $25 \mu \mathrm{g} / \mathrm{g}$ body weight), anti-Dsg1 (40 $\mu \mathrm{g} / \mathrm{g}$ body weight), or anti-Dsg3 (50 $\mu \mathrm{g} / \mathrm{g}$ body weight) IgG with buffer or HDIG (1 mg/g body weight) pretreatment. Mice were examined clinically, and the levels of circulating pathogenic anti-mBP180, anti-Dsg1, and anti-Dsg3 antibodies were quantified 48 hours after IgG injection. HDIG treatment caused a similar degree of reduction in circulating pathogenic IgG levels and blocked clinical blister formation in both WT and $\mathrm{Fc} \gamma \mathrm{RII}{ }^{-/}$mice. IgM control $(6.47 \mathrm{mg} / \mathrm{g}$ body weight) showed results similar to those for buffer control (Table 2). $n=6$ in each group.

disease; $1+$, mild erythematous reaction with no evidence of the epidermal detachment sign elicited by gentle friction of the mouse skin, which, when positive, produced fine, persistent wrinkling of the epidermis; $2+$, intense erythema and epidermal detachment involving $10-50 \%$ of the epidermis in localized areas; and $3+$, intense erythema with frank epidermal detachment involving more than $50 \%$ of the epidermis. The extent of cutaneous disease for IgG passive transfer PF and PV was scored as follows: -, no detectable skin blister when gentle friction of the mouse skin was introduced; $1+$, epidermal wrinkling involving $10-30 \%$ of the epidermis in localized areas; $2+$, epidermal wrinkling involving $30-60 \%$ of the epidermis in localized areas; $3+$, epidermal wrinkling involving more than $60 \%$ of the epidermis in localized areas. Scores for all mice in each group were averaged and expressed as mean disease score \pm SEM. The animals were then sacrificed, and the following specimens were obtained: Skin sections were taken for light microscopy (H\&E staining) and for direct IF analysis to detect bound pathogenic IgG in vivo. Sera of injected animals were obtained for ELISA to determine the circulating levels of antimBP180, anti-Dsg1, and anti-Dsg3. Monospecific FITC-conjugated goat anti-human IgG and FITC-conjugated anti-rabbit IgG were obtained commercially (Kirkegaard \& Perry Laboratories Inc.).

HDIG treatment. Purified human IgG (GAMMAGARD) was obtained from Baxter International Inc. Fifty microliters of IVIG (0-5 mg in PBS/g body weight) was administrated i.p. 2 hours prior to pathogenic IgG injection. IgM (Sigma-Aldrich) at the same molar amount was used as a control for HDIG treatment. Mice with or without HDIG treatment were examined at 24 and 48 hours after pathogenic IgG injection as described above.

Quantification of skin site neutrophil accumulation in experimental BP. Tissue MPO activity in skin sites of the anti-mBP180-injected animals was assayed as described previously (19). A standard reference curve was first established using known concentrations of purified MPO. The skin samples were extracted by homogenization in an extraction buffer containing $0.1 \mathrm{M}$ Tris-Cl, pH 7.6, $0.1 \mathrm{M} \mathrm{NaCl}, 0.5 \%$ hexadecyl trimethylammoniumbromide. MPO activity in the supernatant fraction was measured by the change in
$\mathrm{OD}$ at $460 \mathrm{~nm}$ resulting from decomposition of $\mathrm{H}_{2} \mathrm{O}_{2}$ in the presence of $\mathrm{O}$-dianisidine. MPO content was expressed as units of MPO activity $/ \mathrm{mil}$ ligram protein. Protein concentrations were determined by the Bio-Rad Laboratories Inc. dye binding assay using BSA as a standard.

Quantification of serum levels of rabbit anti-mBP180, human anti-Dsg1, and antiDsg3 IgG. The concentration of serum rabbit anti-mBP180, human antiDsg1, and human anti-Dsg3 IgG were measured by ELISA $(66,74)$. For rabbit anti-mBP180 ELISA, microtiter plates were coated with purified $\mathrm{mBP} 180$ $(1 \mu \mathrm{g} /$ well), incubated with dilutions of serum, developed with HRP-conjugated goat antibodies specific for rabbit $\operatorname{IgG~} \mathrm{F}\left(\mathrm{ab}^{\prime}\right)_{2}$ (Cappel Laboratories), and read at $\mathrm{OD}_{492 \mathrm{~nm}}$ using an ELISA plate reader (Bio-Rad Laboratories Inc.). To quantify serum levels of human anti-Dsg1 and anti-Dsg3 IgG, Ni-NTA microplates (QIAGEN) were coated with purified human Dsg1 and Dsg3 proteins $(1.0 \mu \mathrm{g} /$ well), incubated with dilutions of serum, developed with HRPconjugated mouse monoclonal antibody specific for human IgG (Zymed Laboratories Inc.), and read at $492 \mathrm{~nm}$. For total rabbit IgG ELISA, microtiter plates were coated with $1 \mu \mathrm{g} /$ well of polyclonal goat anti-rabbit IgG Fc antibody (Cappel Laboratories), incubated with dilutions of serum, developed with HRP-conjugated goat antibodies specific for rabbit IgG F(ab') ${ }_{2}$ (Cappel Laboratories), and read at $\mathrm{OD}_{492 \mathrm{~nm}}$ using an ELISA plate reader (Bio-Rad Laboratories Inc.). IgG levels were expressed as relative OD reading (OD reading of samples from mice injected with pathogenic IgG minus OD reading of samples from mice injected with control [buffer or control IgG]). The percent change in IgG levels was calculated by the following formula: [relative OD in IgM- or HDIG-treated mice / relative OD in mice injected with pathogenic IgG alone] $\times 100 \%$. The detection limit for mBP180-, Dsg1-, Dsg3-specific IgG, and total rabbit IgG ELISAs were $0.044 \pm 0.003,0.102 \pm 0.017,0.130 \pm 0.013$, and $0.035 \pm 0.003$ OD reading units, respectively.

In vitro inbibition of pathogenic IgG binding to skin sections. Six-micrometer cryosections were cut from the back skin of neonatal WT and FcRn ${ }^{-/}$mice. Pathogenic rabbit anti-mBP180 $(1 \mathrm{mg} / \mathrm{ml})$, human anti-Dsg1 $(1 \mathrm{mg} / \mathrm{ml})$, and human anti-Dsg3 $(1 \mathrm{mg} / \mathrm{ml})$ IgG were incubated with HDIG $(25 \mathrm{mg} / \mathrm{ml})$ in PBS for 1 hour at room temperature. After centrifugation, the supernatants were diluted 1:1,000, 1:2,000, 1:4,000, and 1:8,000 (detection limit for positive control) for anti-BP180 IgG with PBS and 1:200, 1:400, and 1:800 (detection limit for positive control) for anti-Dsg1 and anti-Dsg3 IgG with PBS-Ca ${ }^{2+}$ and then incubated with skin sections. Anti-BP180 IgG binding to the basement membrane was detected with monospecific FITC-conjugated goat anti-rabbit IgG. Keratinocyte cell surface staining by anti-Dsg1 and anti-Dsg3 was detected with monospecific FITC-conjugated goat anti-human IgG.

Statistics. The data were expressed as mean \pm SEM and were analyzed using the Student's $t$ test. A $P$ value less than 0.05 was considered significant.

\section{Acknowledgments}

We thank Jie Liu and Joy Miller for their excellent technical assistance, Clark Anderson for insightful suggestions, and Lowell Goldsmith for his critical reading of the manuscript. This work was supported in part by US Public Health Service NIH grants AI40768 and AI61430 (to Z. Liu), AR32599 and AR32081 (to L.A. Diaz), and DK56597 and a grant from the Alliance for Lupus Research (to D.C. Roopenian).

Received for publication January 4, 2005, and accepted in revised form September 13, 2005.

Address correspondence to: Zhi Liu, Department of Dermatology, Suite 3100 Thurston Building, University of North Carolina at Chapel Hill, Chapel Hill, North Carolina 27599, USA. Phone: (919) 966-0785; Fax: (919) 966-3898; E-mail: zhiliu@med.unc.edu. 
1. Stanley,J.R. 1999. Bullous pemphigoid. In Fitzpatrick's dermatology in general medicine. I.M. Freedberg, et al., editors. McGraw-Hill. New York, New York, USA. 666-671.

2. Stanley, J.R., Tanaka, T., Mueller, S., Klaus-Kovtun, V., and Roop, D. 1988. Isolation of complementary DNA for bullous pemphigoid antigen by use of patients' autoantibodies. J. Clin. Invest. 82:1864-1870.

3. Sawamura, D., Li, K., Chu, M.-L., and Uitto, J. 1991. Human bullous pemphigoid antigen (BPAG1). Amino acid sequences deduced from cloned cDNAs predict biologically important peptide segments and protein domains. J. Biol. Chem. 266:17784-17790.

4. Diaz, L.A., et al. 1990. Isolation of a human epidermal cDNA corresponding to the $180-\mathrm{kD}$ autoantigen recognized by bullous pemphigoid and herpes gestationis sera. Immunolocalization of this protein to the hemidesmosome. J. Clin. Invest. 86:1088-1094.

5. Giudice, G.J., Emery, D.J., and Diaz, L.A. 1992. Cloning and primary structural analysis of the bullous pemphigoid autoantigen, BP-180. J. Invest. Dermatol. 99:243-250.

6. Giudice, G.J., et al. 1993. Bullous pemphigoid and herpes gestationis autoantibodies recognize a common non-collagenous site on the BP180 ectodomain. J. Immunol. 151:5742-5750.

7.Zillikens, D., et al. 1997. Tight clustering of extracellular BP180 epitopes recognized by bullous pemphigoid autoantibodies. J. Invest. Dermatol. 109:573-579.

8. Nousari, H.C., and Anhalt, G.J. 1999. Pemphigus and bullous pemphigoid. Lancet. 354:667-672.

9. Stanley, J.R. 1993. Cell adhesion molecules as targets of autoantibodies in pemphigus and pemphigoid, bullous disease due to defective epidermal cell adhesion. Adv. Immunol. 53:291-325.

10. Nguyen, V.T., Ndoye, A., and Grando, S.A. 2000. Pemphigus vulgaris antibody identifies pemphaxin. A novel keratinocyte annexin-like molecule binding acetylcholine. J. Biol. Chem. 275:29466-29476.

11. Nguyen, V.T., Ndoye, A., and Grando, S.A. 2000. Novel human $\alpha 9$ acetylcholine receptor regulating keratinocyte adhesion is targeted by pemphigus vulgaris autoimmunity. Am. J. Pathol. 157:1377-1391.

12. Kalish, R.S. 2000. Pemphigus vulgaris: the other half of the story. J. Clin. Invest. 106:1433-1435.

13. Anhalt, G.J., Labib, R.S., Voorhees, J.J., Beals, T.F., and Diaz, L.A. 1982. Induction of pemphigus in neonatal mice by passive transfer of IgG from patients with the disease. N. Engl. J. Med. 306:1189-1196.

14. Roscoe, J.T., et al. 1985. Brazilian pemphigus foliaceus autoantibodies are pathogenic to BALB/c mice by passive transfer. J. Invest. Dermatol. 85:538-541.

15. Amagai, M., Karpati, S., Prussick, R., Klaus-Kovtun, V., and Stanley, J.R. 1992. Autoantibodies against the amino-terminal cadherin binding domain of pemphigus vulgaris antigen are pathogenic. J. Clin. Invest. 90:919-926.

16. Amagai, M., Hashimoto, T., Green, K.J., Shimizu, N., and Nishikawa, T. 1995. Antigen-specific immunoadsorption of pathogenic autoantibodies in pemphigus foliaceus. J. Invest. Dermatol. 104:895-901.

17. Liu, Z., et al. 1993. A passive transfer model of the organ-specific autoimmune disease, bullous pemphigoid, using antibodies generated against the hemidesmosomal antigen, BP180. J. Clin. Invest. 92:2480-2488.

18. Liu, Z., et al. 1995. The role of complement in experimental bullous pemphigoid. J. Clin. Invest. 95:1539-1544.

19. Liu, Z., et al. 1997. A major role for neutrophils in experimental bullous pemphigoid. J. Clin. Invest.
100:1256-1263.

20. Chen, R., Zhou, X., Diaz, L.A., Werb, Z., and Liu, Z. 2001. Mast cells play a key role in neutrophil recruitment in experimental bullous pemphigoid. J. Clin. Invest. 108:1151-1158. doi:10.1172/JCI200111494.

21. Yancey, K.B., and Egan, C.A. 2000. Pemphigoid: clinical, histologic, immunologic, and therapeutic considerations. JAMA. 284:350-356.

22. Toth, G.G., and Jonkman, M.F. 2001. Therapy of pemphigus. Clin. Dermatol. 19:761-767.

23. Khumalo, N.P., Murrell, D.F., Wojnarowska, F., and Kirtschig, G. 2002. A systematic review of treatments for bullous pemphigoid. Arch. Dermatol. 138:385-389.

24. Dutz, J.P., and Ho, V.C. 1998. Immunosuppressive agents in dermatology: an update. Dermatol. Clin. 16:235-251.

25. Kazatchkine, M.D., and Kaveri, S.V. 2001. Immunomodulation of autoimmune and inflammatory diseases with intravenous immune globulin. N. Engl. J. Med. 345:747-755.

26. Gelfand, E.W. 2001. Antibody-directed therapy: past, present and future. J. Allergy Clin. Immunol. 108:S111-S116.

27. van der Meche, F.G., and Schmitz, P.I. 1992. A randomized trial comparing intravenous immune globulin and plasma exchange in Guillain-Barre syndrome. Dutch Guillain-Barre Study Group. N. Engl.J. Med. 326:1123-1129.

28. Gajdos, P., et al. 1984. High-dose intravenous gammaglobulin for myasthenia gravis. Lancet. 1:406-407.

29. Sultan, Y., Kazatchkine, M.D., Maisonneuve, P., and Nydegger, U.E. 1984. Anti-idiotypic suppression of autoantibodies to factor VIII (antihaemophilic factor) by high-dose intravenous gammaglobulin. Lancet. 2:765-768.

30. Dalakas, M.C., et al. 1993. A controlled trial of high-dose intravenous immune globulin infusions as treatment for dermatomyositis. N. Engl. J. Med. 329:1993-2000.

31. Jayne, D.R., Davies, M.J., Fox, C.J., Black, C.M., and Lockwood, C.M. 1991. Treatment of systemic vasculitis with pooled intravenous immunoglobulin. Lancet. 337:1137-1139.

32. LeHoang, P., Cassoux, N., George, F., Kullmann, N., and Kazatchkine, M.D. 2000. Intravenous immunoglobulin (IVIg) for the treatment of birdshot retinochoroidopathy. Ocul. Immunol. Inflamm. 8:49-57.

33. Jolles, S. 2001. A review of high-dose intravenous immunoglobulin (hdIVIg) in the treatment of the autoimmune blistering disorders. Clin. Exp. Dermatol. 26:127-131.

34. Ahmed, A.R., and Dahl, M.V. 2003. Consensus statement on the use of intravenous immunoglobulin therapy in the treatment of autoimmune mucocutaneous blistering diseases. Arch. Dermatol. 139:1051-1059.

35. Ballow, M. 1997. Mechanisms of action of intravenous immune serum globulin in autoimmune and inflammatory diseases. J. Allergy Clin. Immunol. 100:151-157.

36. Debre, M., et al. 1993. Infusion of Fc gamma fragments for treatment of children with acute immune thrombocytopenic purpura. Lancet. 342:945-949.

37. Soubrane, C., et al. 1993. Biologic response to antiCD16 monoclonal antibody therapy in a human immunodeficiency virus-related immune thrombocytopenic purpura patient. Blood. 81:15-19.

38. Clarkson, S.B., et al. 1986. Treatment of refractory immune thrombocytopenic purpura with an anti-Fc gamma-receptor antibody. N. Engl. J. Med. 314:1236-1239.

39. Mouthon, L., et al. 1996. Mechanisms of action of intravenous immune globulin in immune-mediated diseases. Clin. Exp. Immunol. 104:3-9.

40. Viard, I., et al. 1998. Inhibition of toxic epidermal necrolysis by blockade of CD95 with human intravenous immunoglobulin. Science. 282:490-493.

41. Crow, A.R., Song, S., Semple, J.W., Freedman, J., and Lazarus, A.H. 2001. IVIg inhibits reticuloendothelial system function and ameliorates murine passiveimmune thrombocytopenia independent of antiidiotype reactivity. Br. J. Haematol. 115:679-686.

42. Masson, P.L. 1993. Elimination of infectious antigens and increase of IgG catabolism as possible modes of action of IVIg. J. Autoimmun. 6:683-689.

43. Yu, Z., and Lennon, V.A. 1999. Mechanism of intravenous immune globulin therapy in antibodymediated autoimmune diseases. N. Engl. J. Med. 340:227-228.

44. Bleeker, W.K., Teeling, J.L., and Hack, C.E. 2001. Accelerated autoantibody clearance by intravenous immunoglobulin therapy: studies in experimental models to determine the magnitude and time course of the effect. Blood. 98:3136-3142.

45. Pierangeli, S.S., Espinola, R., Liu, X., Harris, E.N., and Salmon, J.E. 2001. Identification of an Fcy receptor-independent mechanism by which intravenous immunoglobulin ameliorates antiphospholipid antibody-induced thrombogenic phenotype. Arthritis Rheum. 44:876-883.

46. Hansen, R.J., and Balthasar, J.P. 2002. Effects of intravenous immunoglobulin on platelet count and antiplatelet antibody disposition in a rat model of immune thrombocytopenia. Blood. 100:2087-2093.

47. Hansen, R.J., and Balthasar, J.P. 2002. Intravenous immunoglobulin mediates an increase in antiplatelet antibody clearance via the FcRn receptor. Thromb. Haemost. 88:898-899.

48. Samuelsson, A., Towers, T.L., and Ravetch, J.V. 2001. Anti-inflammatory activity of IVIG mediated through the inhibitory Fc receptor. Science. 291:484-486

49. Bruhns, P., Samuelsson, A., Pollard, J.W., and Ravetch, J.V. 2003. Colony-stimulating factor-1-dependent macrophages are responsible for IVIG protection in antibody-induced autoimmune disease. Immunity. 18:573-581.

50. Akilesh, S., et al. 2004. The MHC class I-like Fc receptor promotes humorally mediated autoimmune disease. J. Clin. Invest. 113:1328-1333. doi:10.1172/JCI200418838.

51. Takai, T., Ono, M., Hikida, M., Ohmori, H., and Ravetch, J.V. 1996. Augmented humoral and anaphylactic responses in Fc gamma RII-deficient mice. Nature. 379:346-349.

52. Clynes, R., et al. 1999. Modulation of immune complex-induced inflammation in vivo by the coordinate expression of activation and inhibitory Fc receptors. J. Exp. Med. 189:179-186.

53. van Lent, P., et al. 2003. The inhibitory receptor FcRII reduces joint inflammation and destruction in experimental immune complex-mediated arthritides not only by inhibition of FcRI/III but also by efficient clearance and endocytosis of immune complexes. Am. J. Pathol. 163:1839-1848.

54. Stefanescu, R.N., Olferiev, M., Liu, Y., and Pricop, L. 2004. Inhibitory Fc gamma receptors: from gene to disease. J. Clin. Immunol. 24:315-326.

55. Simister, N.E., and Mostov, K.E. 1989. An Fc receptor structurally related to MHC class I antigen. Nature. 337:184-187.

56. Story, C.M., Mikulska, J.E., and Simister, N.E. 1994. A major histocompatibility complex class Ilike Fc receptor cloned from human placenta: possible role in transfer of immunoglobulin $\mathrm{G}$ from mother to fetus. J. Exp. Med. 180:2377-2381.

57. Israel, E.J., et al. 1997. Expression of the neonatal FC receptor, FcRn, on human intestinal epithelial cells. Immunology. 92:69-74.

58. Junghans, R.P., and Anderson, C.L. 1996. The protection receptor for IgG catabolism is the beta2microglobulin-containing neonatal intestinal 
transport receptor. Proc. Natl. Acad. Sci. U. S. A. 93:5512-5516.

59. Roberts, D.M., Guenthert, M., and Rodewald, R. 1990. Isolation and characterization of the $\mathrm{FC}_{\mathrm{C}}$ receptor from the fetal yolk sac of the rat. J. Cell Biol. 111:1867-1876.

60. Zijlstra, M., et al. 1990. Beta 2-microglobulin deficient mice lack CD4-8+ cytolytic T cells. Nature. 344:742-746.

61. Medesan, C., Radu, C., Kim, J.K., Ghetie, V., and Ward, E.S. 1996. Localization of the site of the IgG molecule that regulates maternofetal transmission in mice. Eur. J. Immunol. 26:2533-2536.

62. Ghetie, V., et al. 1996. Abnormally short serum halflives of IgG in beta 2-microglobulin-deficient mice. Eur. J. Immunol. 26:690-696.

63. Israel, E.J., Wilsker, D.F., Hayes, K.C., Schoenfeld, D., and Simister, N.E. 1996. Increased clearance of IgG in mice that lack beta 2-microglobulin: possible protective role of FcRn. Immunology 89:573-578.

64. Christianson, G.J., et al. 1997. Beta 2-microglobulin-deficient mice are protected from hypergamma- globulinemia and have defective antibody responses because of increased IgG catabolism. J. Immunol. 159:4781-4792.

65. Roopenian, D.C., et al. 2003. The MHC class-I like IgG receptor controls perinatal IgG transport, IgG homeostasis, and fate of IgG-Fc-coupled drugs. J. Immunol. 170:3528-3533.

66. Liu, Z., et al. 1997. $\beta 2$ microglobulin-deficient mice are resistant to bullous pemphigoid. J. Exp. Med. 186:777-783

67. Amagai, M., Nishikawa, T., Nousari, H.C., Anhalt, G.J., and Hashimoto, T. 1998. Antibodies against desmoglein 3 (pemphigus vulgaris antigen) are present in sera from patients with paraneoplastic pemphigus and cause acantholysis in vivo in neonatal mice. J. Clin. Invest. 102:775-782.

68. Morrison, L.H., Labib, R.S., Zone, J.J., Diaz, L.A., and Anhalt, G.J. 1988. Herpes gestationis autoantibodies recognize a $180-\mathrm{kD}$ human epidermal antigen. J. Clin. Invest. 81:2023-2026.

69. Bernard, P., et al. 1992. The major cicatricial pemphigoid antigen is a $180-\mathrm{kD}$ protein that shows immunologic cross-reactivities with the bullous pemphigoid antigen. J. Invest. Dermatol. 99:174-179.

70. Tamada, Y., et al. 1999. Lichen planus pemphigoides: identification of $180 \mathrm{kD}$ hemidesmosome antigen. J. Am. Acad. Dermatol. 32:883-887.

71. Siragam, V., et al. 2005. Can antibodies with specificity for soluble antigens mimic the therapeutic effects of IVIG in the treatment of autoimmune disease? J. Clin. Invest. 115:155-160. doi:10.1172/ JCI200522753.

72. Li, N., Aoki, V., Hans-Filho, G., Rivitti, E.A., and Diaz, L.A. 2003. The role of intramolecular epitope spreading in the pathogenesis of endemic pemphigus foliaceus (fogo selvagem). J. Exp. Med. 197:1501-1510.

73. Liu, Z., et al. 1995. Molecular mapping of a pathogenically relevant BP180 epitope associated with experimentally induced murine bullous pemphigoid. J. Immunol. 155:5449-5454.

74. Warren, S.J., et al. 2003. The role of subclass switching in the pathogenesis of endemic pemphigus foliaceus. J. Invest. Dermatol. 120:104-108. 